\title{
Cervical level llb metastases in squamous cell carcinoma of the oral cavity: a systematic review and meta-analysis
}

This article was published in the following Dove Press journal:

OncoTargets and Therapy

II September 2017

Number of times this article has been viewed

\author{
Yurong Kou',* \\ Tengfei Zhao ${ }^{2, *}$ \\ Shaohui Huang ${ }^{2}$ \\ Jie Liu ${ }^{3}$ \\ Weiyi Duan ${ }^{2}$ \\ Yunjing Wang ${ }^{2}$ \\ Zechen Wang ${ }^{2}$ \\ Delong $\mathrm{Li}^{2}$ \\ Chunliu Ning ${ }^{2}$ \\ Changfu Sun ${ }^{2}$ \\ 'Department of Oral Biology, \\ School of Stomatology, China \\ Medical University, Shenyang, \\ Liaoning, People's Republic of China; \\ ${ }^{2}$ Department of Oral and Maxillofacial \\ Surgery, School of Stomatology, \\ China Medical University, Shenyang, \\ Liaoning, People's Republic of China; \\ ${ }^{3}$ Centre of Science Experiment, China \\ Medical University, Shenyang, Liaoning, \\ People's Republic of China \\ *These authors contributed equally \\ to this work
}

\begin{abstract}
Purpose: The aim of this study was to clarify whether level IIb dissection should be performed or avoided in the treatment of oral squamous cell carcinoma by meta-analysis.

Materials and methods: Articles that were published before June 2017 were searched electronically in four databases (Web of Science, PubMed, Ovid and China National Knowledge Infrastructure) without any date or language restrictions by two independent reviewers. Abstracts and full-text papers which investigated the cervical metastases to level IIb from primary head and neck cancers and were deemed potentially relevant were screened. Data were analyzed using RevMan 5.3.

Results: Four hundred and fifty-five abstracts and 129 full-text papers were screened, and 22 studies were included in the analysis. Among the 2001 patients included, 112 patients had level IIb metastases, the pooled frequency of which was $6 \%(95 \%$ confidence interval $[\mathrm{CI}]$ : 4.0-7.0). Among the 400 patients with tongue squamous cell carcinoma from 12 studies, 37 patients had level IIb metastases, the pooled incidence of which was 7\% (95\% CI: 5.0-10.0). Metastases to level IIb always went together with level IIa, and only three patients were found to have isolated level IIb metastases without involving the other levels.

Conclusion: Due to the low frequency of level IIb nodal metastases in oral squamous cell carcinoma patients and rare occurrence of isolated level IIb, level IIb dissection could be avoided when the primary lesions were in early stages (T1 and T2), with the exception of tongue cancer. It is recommended to dissect level IIb tongue cancers without considering the stages of primary lesions and the lymph nodes status. It is also suggested that level IIb dissection should be performed in patients preoperatively or intraoperatively found with multilevel neck metastasis, especially level IIa metastasis.
\end{abstract}

Keywords: level IIb, meta-analysis, neck dissection, oral squamous cell carcinoma, submuscular recess

\section{Introduction}

Oral squamous cell carcinoma (OSCC) is a life-threatening malignant tumor which accounts for $32 \%-40 \%$ of all the head and neck cancers. It characteristically metastasizes via lymphatic vessels to cervical lymph nodes. ${ }^{1,2}$ According to statistics, the incidence of clinical cervical metastases from OSCC was as high as $40 \%{ }^{3}$ Even among patients with no clinical or radiologic evidence of lymph node metastases preoperatively, occult regional lymph node metastases were revealed by pathohistologic and immunohistochemical analysis with an incidence of $15 \%-34 \% .{ }^{4}$ Cervical lymph node status is the most significant prognostic factor in the treatment of patients with OSCC. Once the tumor involves the neck nodes, survival drops by almost $50 \%$.
Correspondence: Shaohui Huang Department of Oral and Maxillofacial Surgery, School of Stomatology, China Medical University, No I I 7 Nanjing Bei Jie, Heping District, Shenyang, Liaoning I I 0002, People's Republic of China Tel/fax +8602431927739

Email huangshaohui@hotmail.com 
Neck dissection, therefore, plays an important role in management of oral cancers, not only as a part of routine treatment, but also as a diagnostic and prognostic approach to determine adjuvant therapy based on their stages and histopathologic characteristics. The techniques of neck dissection have evolved significantly over time, from radical neck dissection to selective neck dissection (SND), with improved functional results. Surgeons have reached a consensus that it is desirable to perform the least radical surgical approach while retaining maximum locoregional control and not sacrificing the survival rate. ${ }^{5-8}$ Supraomohyoid neck dissection, an $\mathrm{SND}$, is now the most commonly used surgical technique for detecting occult metastatic cervical lymph nodes and treating the clinically N0 neck. Supraomohyoid neck dissection removes the contents in levels I-III, to which oral cavity cancer most frequently spreads via lymphatic drainage, ${ }^{9,10}$ but preserves functionally important anatomic structures, such as the sternocleidomastoid muscle, the internal jugular vein, and the spinal accessory nerve (SAN).

As the cervical level II is one of the most likely regions to which OSCC tends to metastasize, meticulous dissection is needed in this area. ${ }^{8}$ However, the posterior region of level II, which is called level IIb, is technically more challenging for surgeons and puts patients at a higher risk because of its crucial anatomic position, difficult accessibility, and important anatomic contents. The SAN splits level II into sublevels IIa and IIb. ${ }^{11,12}$ The sublevel IIb, also called submuscular recess, is a triangular area bounded anteromedially by the SAN, superiorly by the skull base, inferiorly by the horizontal plane defined by the hyoid bone, and posteriorly by the posterior border of the sternocleidomastoid muscle. Lymph nodes in this region surround the upper internal jugular vein and SAN. Adequate clearance of level IIb lymph nodes requires traction and elevation of the SAN. This may lead to consequent shoulder problems ranging from a difficulty at overhead abduction to a frozen shoulder due to neurapraxia and devascularization induced by dissection. ${ }^{13}$ Therefore, avoiding the dissection of level IIb has been increasingly proposed in order to overcome this complication. Some groups stated that the incidence of metastases to level IIb was rather low in OSCC. But the incidence of metastases to level IIb remains controversial, and despite various published literature, the necessity of level IIb dissection needs to be discussed further. ${ }^{14-19}$

Hence, the purpose of this study is to clarify whether level IIb dissection should be performed or avoided in the treatment of OSCC by analyzing the frequency of metastases to level IIb with meta-analysis. The answer to this question may have some guiding significance on the clinical management strategy for OSCC.

\section{Materials and methods \\ Search strategy}

Search terms used were neck dissection, submuscular recess, level IIb, upper jugular lymph nodes, posterior triangle apex, mouth neoplasms, mouth mucosa, oral cavity and squamous cell neoplasms. Electronic searches were conducted in Web of Science, PubMed, Ovid and China National Knowledge Infrastructure for articles that were published until June 2017, without restrictions on dates or language. Studies that were cited in the reference lists of the included papers were also evaluated to ensure inclusion of all relevant studies.

\section{Inclusion and exclusion criteria}

Inclusion criteria were: 1) studies that investigated the frequency of cervical metastases to level IIb from primary head and neck cancers; 2) OSCC patients' data should be extractable from the articles included and 3) the studies included should have histologically analyzed level IIb separately from the other levels for the presence of metastases. Exclusion criteria were: 1) studies on patients who had undergone preoperative radiotherapy and chemotherapy and 2) studies on tumors that relapsed.

\section{Data extraction}

Information was extracted from the included studies, such as authors, publication year, recruitment years, total OSCC cases, cases of IIb metastases and frequency of metastases. Data extraction was independently performed by two authors, Yurong Kou and Tengfei Zhao. Disagreements were solved by discussion or consultation with another author, Shaohui Huang.

\section{Quality evaluation}

Quality evaluation of literature was conducted according to the evaluation criteria for cross-sectional studies recommended by the Agency for Healthcare Research and Quality, as shown in Table 1. Each included literature was evaluated as "yes" or "no" or "unclear" by the 11 entries of the evaluation criteria. If the number of "yes" for a literature was $\geq 7$, the quality of the literature was ranked high; if it was at the range of 4-6, the quality of the literature was ranked medium and if it was $\leq 3$, the quality of the literature was ranked low. 
Table I The literature quality evaluation of AHRQ

Item
I) Define the source of information (survey,
record review)
2) List the inclusion and exclusion criteria for
exposed and unexposed subjects (cases and
controls) or refer to previous publications
3) Indicate the time period used for identifying
patients
4) Indicate whether or not subjects were
consecutive, if not population based
5) Indicate if evaluators of subject
components of the study were masked
to other aspects of the status of the
participants
6) Describe any assessments undertaken for
quality assurance purposes (eg, test/retest
of primary outcome measurements)
7) Explain any patient exclusions from
the analysis
8) Describe how confounding was assessed
and/or controlled
9) If applicable, explain how missing data were
handled in the analysis
10) Summarize patient response rates and
completeness of data collection
11) Clarify what follow-up, if any, was expected
and the percentage of patients for which
incomplete data or follow-up was obtained

Abbreviation: AHRQ, Agency for Healthcare Research and Quality.

\section{Statistical analysis}

Data synthesis and statistical analysis were performed with RevMan5.3. Risk difference, standard error and 95\% CI were pooled to analyze the incidence of level IIb metastases. As there was no single rate analysis in the RevMan meta-analysis options, generic inverse variance was chosen to calculate the pooled effect, risk difference and rate were logically equivalent. Chi-square based $\mathrm{Q}$ test and $I^{2}$ were used for heterogeneity evaluation. When $P>0.10$ and $I^{2}<50 \%$, a fixed-effects model was used; when $P<0.10$ or $I^{2}>50 \%$, a random effects model was used.

\section{Results}

The search and selection process of the articles is presented in Figure 1. Briefly, based on the selection criteria, a total of 453 articles were identified by the database search and 2 additional articles were found through reviewing articles and reference lists of retrieved articles and preprint online publications. After the duplicates were removed, 203 articles were screened by their titles and abstracts and 60 were subsequently retained. After full-text revision, 38 articles were excluded for various reasons. Thus, 22 studies, all published in English, were included for further analysis. ${ }^{15,18-38}$

\section{Description of the studies}

By quality evaluation, 12 references ranked high, 7 references ranked medium and only 3 references ranked low. Data of 2001 patients were pooled for statistical analysis. In the 22 studies, 112 cases of cervical IIb metastasis were confirmed by pathologic examination or other technologies. But the inclusion criteria and the exclusion criteria of these studies were somewhat inconsistent. Five studies recruited only OSCC patients with clinical N0; seven studies gave the absolute numbers of clinical $\mathrm{N} 0$ and $\mathrm{N}+$ cases respectively, while 10 studies provided no information about the clinical lymph node status. Table 2 summarizes the details of the studies included.

Thirteen articles illustrated the characteristics of cervical IIb metastasis patients, which gave details of sites, T stages, isolated IIb metastases and associated metastatic lymph nodes. However, not all the information was complete for each study. The most common primary site for level $\mathrm{IIb}$ metastases was the tongue, and tongue cancer particularly has a tendency toward early metastasis (T1 and T2). The other primary sites for level IIb metastases were retromolar trigone, buccal mucosa, floor of the mouth and alveolar ridge and the cases were relatively few. It was also presented that metastases at level IIb always went together with level IIa, and only three patients were found to have isolated level IIb metastases without involving the other levels. Table 3 provides a summary of patient characteristics with level $\mathrm{IIb}$ metastases.

Table 4 lists special information about the tongue squamous cell carcinoma (SCC) cervical level IIb metastases. Among 400 tongue SCC patients from 12 studies, metastases to level IIb lymph nodes were found in 37 cases and the frequency of level IIb metastases ranged from $5.00 \%$ to $21.74 \%$.

\section{Results of the pooled analysis}

The forest plots for cervical level IIb metastasis rate of OSCC showed that the pooled estimated cervical level IIb metastasis rate was $6 \%(95 \% \mathrm{CI}: 4.0-7.0)$ using a random effects model (Figure 2). The corresponding Funnel plots indicated that most of the research was close to axis and there were no publication bias in these studies (Figure 3).

The forest plots for cervical level IIb metastasis rate of tongue SCC showed that the cervical IIb metastasis rate for 


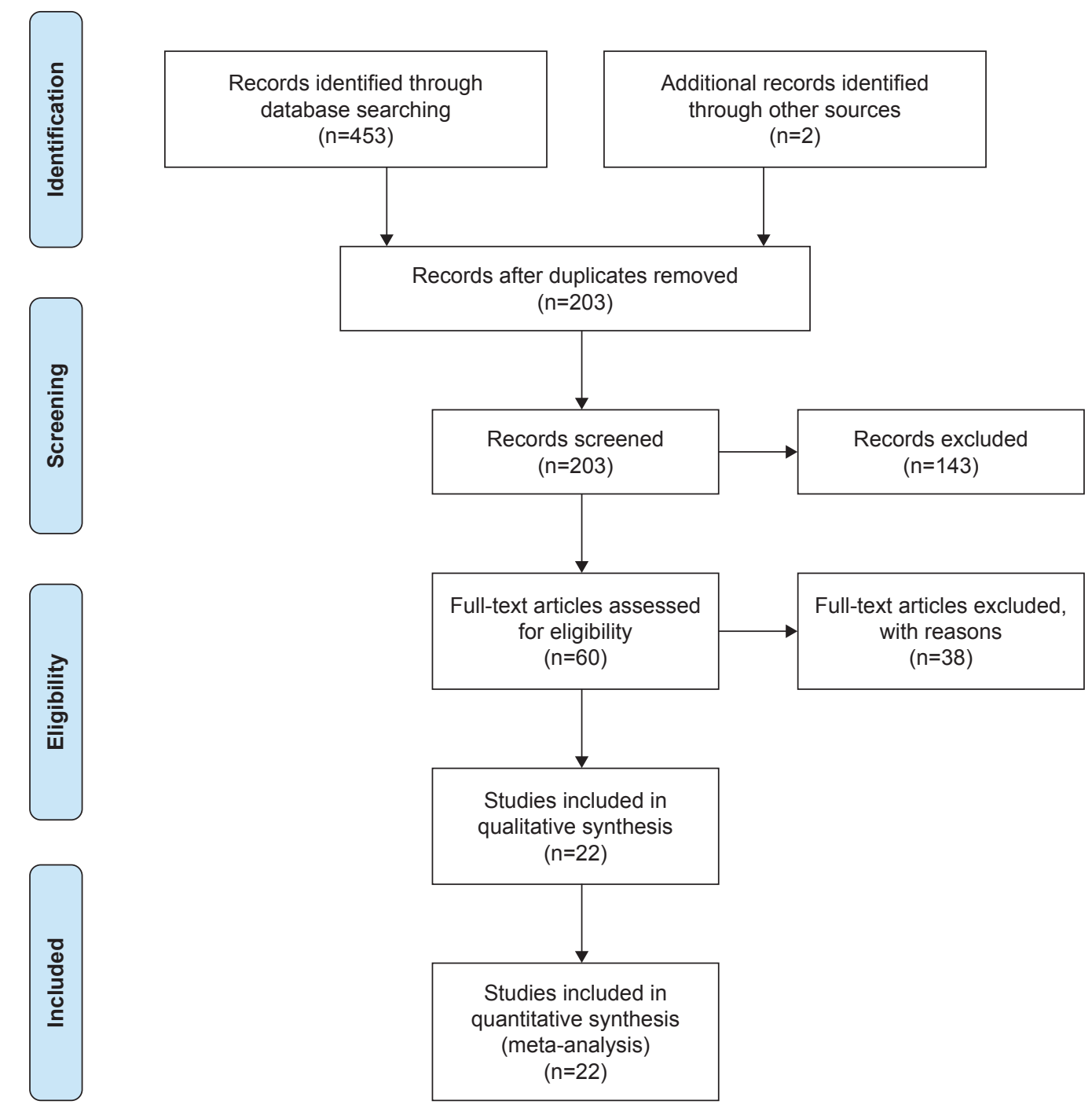

Figure I Flow diagram for the identified published studies included in the meta-analysis.

tongue SCC was 7\% (95\% CI: 5.0-10.0; Figure 4) using a fixed-effects model. The relevant Funnel plots indicated that there was no publication bias in these 12 studies (Figure 5).

\section{Sensitivity analysis}

Sensitivity analysis was conducted to test the stability of this meta-analysis. The data in the largest and minimum weight were deleted respectively to examine the influence of the deleted data on the pooled rates. With a random effects model, the pooled estimated cervical level $\mathrm{IIb}$ metastases rate was $6 \%(95 \% \mathrm{CI}: 4.0-7.0)$. When the data in the largest weight ${ }^{25}$ were removed, the result was 5\% $(95 \%$ CI: 4.0-6.0), and when the data in the minimum weight ${ }^{38}$ were deleted, the result was 5\% (95\% CI: 4.0-7.0). With a fixed-effects model, the pooled estimated cervical IIb metastases rate for tongue SCC was 7\% (95\% CI: 5.0-10.0). Then the same method of sensitivity analysis was used for the level IIb pooled metastases rate of tongue SCC and the results were 9\% (95\% CI: $6.0-13.0)$ and $10.8 \%$ (95\% CI: 10.5-11.0), respectively. Deletion of the data in the largest or minimum weight had a negligible influence on the pooled metastasis rate, which indicated the good stability of this meta-analysis.

\section{Discussion}

The aim of SND is to reduce morbidity by preserving the SAN, the sternomastoid muscle and the internal jugular vein. The SAN is important in supplying motor function to the trapezius in the majority of people, and sacrifice of this 
Table 2 Information from 22 studies included in the analysis

\begin{tabular}{|c|c|c|c|c|c|c|c|}
\hline Authors & Year & $\begin{array}{l}\text { Recruitment } \\
\text { years }\end{array}$ & $\begin{array}{l}\text { Total } \\
\text { OsCC cases }\end{array}$ & cNO & $\mathbf{c N}+$ & $\begin{array}{l}\text { The OSCC } \\
\text { cases of IIb } \\
\text { metastases }\end{array}$ & $\begin{array}{l}\text { Metastatic } \\
\text { rate, \% }\end{array}$ \\
\hline Lim et al ${ }^{15}$ & 2004 & $|997-200|$ & 74 & 74 & 0 & 4 & 5.00 \\
\hline De Vicente et $\mathrm{al}^{20}$ & 2015 & $2010-2011$ & 56 & 27 & 29 & I & 1.80 \\
\hline Maher and Hoffman ${ }^{21}$ & 2014 & $2006-2013$ & 71 & 71 & 0 & 4 & 5.60 \\
\hline Koerdt et al ${ }^{18}$ & 2016 & $20|I-20| 4$ & 112 & - & - & 16 & 12.60 \\
\hline Bartella et $\mathrm{al}^{22}$ & 2016 & $2012-2015$ & 183 & 116 & 67 & 6 & 3.30 \\
\hline Manola et al ${ }^{19}$ & 2011 & $2002-2006$ & 38 & 16 & 22 & 8 & 21.00 \\
\hline Smith et $\mathrm{al}^{23}$ & 2007 & $2002-2004$ & 34 & - & - & 3 & 8.00 \\
\hline Hoyt et al ${ }^{24}$ & 2008 & $2002-2006$ & 78 & 46 & 32 & 5 & 6.40 \\
\hline Agarwal et a $\left.\right|^{25}$ & 2016 & $2011-2015$ & 231 & 231 & 0 & 2 & 0.86 \\
\hline Bhattacharya et $\mathrm{al}^{26}$ & 2015 & - & 30 & - & - & 2 & 6.67 \\
\hline Corlette et $\mathrm{al}^{27}$ & 2005 & 1998-2003 & 56 & - & - & 4 & 7.14 \\
\hline Chone et $\mathrm{al}^{28}$ & 2000 & $1988-1997$ & 25 & - & - & I & 3.60 \\
\hline Elsheikh et $\mathrm{al}^{29}$ & 2005 & $200 I-2004$ & 48 & 48 & 0 & 5 & 10.40 \\
\hline Talmi et a ${ }^{30}$ & 1998 & $1995-1996$ & 33 & - & - & 2 & 6.06 \\
\hline Santoro et $\mathrm{al}^{31}$ & 2008 & 2004-2007 & 47 & 40 & 7 & I & 2.13 \\
\hline Silverman et $\mathrm{al}^{32}$ & 2003 & $|998-200|$ & 35 & - & - & I & 2.86 \\
\hline Pantvaidya et $\mathrm{a}^{33}$ & 2014 & $2008-2011$ & 583 & - & - & 22 & 3.80 \\
\hline Villaret et $\mathrm{al}^{34}$ & 2007 & $2003-2005$ & 111 & 54 & 57 & 11 & 9.91 \\
\hline Dabholkar and Kapre ${ }^{35}$ & 2016 & $2011-2012$ & 65 & - & - & 7 & 10.44 \\
\hline Ghantous et $\mathrm{a}^{36}$ & 2016 & $2000-2011$ & 70 & 35 & 35 & 5 & 7.14 \\
\hline Paleri et $\mathrm{al}^{37}$ & 2007 & - & 10 & - & - & I & 2.60 \\
\hline Chiesa et $\mathrm{al}^{38}$ & 2000 & $1997-1998$ & 11 & 11 & 0 & I & 9.09 \\
\hline Total cases & & & 2001 & 769 & 249 & 112 & \\
\hline
\end{tabular}

Note: “-”, Data not provided.

Abbreviation: OSCC, oral squamous cell carcinoma.

nerve causes significant shoulder dysfunction and pain. Some authors have reported that even if the SAN is preserved, some degree of shoulder morbidity could occur. ${ }^{13,39}$ Leipzig et al concluded that there may be a degree of shoulder dysfunction associated with any type of neck dissection, even when the SAN is minimally dissected or stretched. ${ }^{40}$ Kraus et al reported that $50 \%$ of patients who underwent SAN-sparing procedures experienced shoulder drop, while $30 \%$ of those

Table 3 A summary of patient characteristics among those with level llb metastases

\begin{tabular}{|c|c|c|c|c|c|c|c|c|c|c|c|}
\hline \multirow[t]{3}{*}{ Authors } & \multirow[t]{3}{*}{ Year } & \multirow[t]{3}{*}{ Cases } & \multirow{3}{*}{$\begin{array}{l}\text { Ilb metastases } \\
\text { cases }\end{array}$} & \multicolumn{6}{|c|}{ Ilb metastases patients' specific information } & \multirow{3}{*}{$\begin{array}{l}\text { Isolated IIb } \\
\text { metastases }\end{array}$} & \multirow{3}{*}{$\begin{array}{l}\text { Distribution of } \\
\text { positive level lymph } \\
\text { nodes (for cases Ilb+) }\end{array}$} \\
\hline & & & & \multirow[t]{2}{*}{ Site } & \multirow[t]{2}{*}{ Cases } & \multicolumn{4}{|c|}{$T$ (no) } & & \\
\hline & & & & & & TI & T2 & T3 & $\overline{\text { T4 }}$ & & \\
\hline Lim et $a^{15}$ & 2004 & 74 & 4 & Tongue & 4 & - & 4 & - & - & 0 & I, Ila, III \\
\hline De Vicente et $\mathrm{al}^{20}$ & 2015 & 56 & I & Tongue & 1 & I & - & - & - & 0 & Ila, III \\
\hline \multirow[t]{2}{*}{ Maher and Hoffman ${ }^{21}$} & 2014 & 71 & 4 & Tongue & 3 & - & 2 & I & - & 2 & Ila, III \\
\hline & & & & Retromolar trigone & I & - & - & - & I & - & - \\
\hline Smith et $\mathrm{al}^{23}$ & 2007 & 34 & 3 & - & - & - & I & - & 2 & - & - \\
\hline Hoyt et $\mathrm{al}^{24}$ & 2008 & 78 & 5 & - & - & - & 2 & I & 2 & - & - \\
\hline Agarwal et al ${ }^{25}$ & 2016 & 231 & 2 & Buccal mucosa & - & - & - & - & - & - & - \\
\hline \multirow[t]{2}{*}{ Bhattacharya et $\mathrm{al}^{26}$} & 2015 & 30 & 2 & Anterior alveolus mandible & I & I & - & - & - & 0 & Ila \\
\hline & & & & Buccal mucosa & 1 & - & I & - & - & - & - \\
\hline Elsheikh et $\mathrm{al}^{29}$ & 2005 & 48 & 5 & - & - & - & - & - & - & 0 & Illa \\
\hline \multirow[t]{2}{*}{ Talmi et $\mathrm{al}^{30}$} & 1998 & 33 & 2 & Tongue & I & - & - & - & - & - & - \\
\hline & & & & Alveolar ridge & I & - & - & - & I & - & - \\
\hline Santoro et $\mathrm{al}^{31}$ & 2008 & 47 & I & - & - & - & I & - & - & 0 & Ila \\
\hline Silverman et $\mathrm{al}^{32}$ & 2003 & 35 & I & - & - & - & - & - & 1 & 0 & Ila, III \\
\hline Paleri et $\mathrm{al}^{37}$ & 2007 & 10 & I & FOM & - & - & - & - & I & I & - \\
\hline Chiesa et $\mathrm{al}^{38}$ & 2000 & II & I & Tongue & 1 & I & - & - & - & - & - \\
\hline
\end{tabular}

Note: “-”, Data not provided.

Abbreviation: FOM, floor of mouth. 
Table 4 Special information about the tongue squamous cell carcinoma

\begin{tabular}{|c|c|c|c|c|}
\hline Authors & Year & $\begin{array}{l}\text { Total } \\
\text { tongue } \\
\text { SCC cases }\end{array}$ & $\begin{array}{l}\text { Tongue } \\
\text { SCC cases } \\
\text { of Ilb } \\
\text { metastases }\end{array}$ & $\begin{array}{l}\text { Tongue } \\
\text { SCC Ilb } \\
\text { metastases } \\
\text { rate, \% }\end{array}$ \\
\hline Lim et $\mathrm{al}^{15}$ & 2004 & 51 & 4 & 7.84 \\
\hline De Vicente et $\mathrm{al}^{20}$ & 2015 & 20 & 1 & 5.00 \\
\hline Maher and Hoffman ${ }^{21}$ & 2014 & 27 & 3 & II.II \\
\hline Koerdt et al ${ }^{18}$ & 2016 & 40 & 3 & 7.50 \\
\hline Manola et al ${ }^{19}$ & 2011 & 38 & 8 & 21.05 \\
\hline Elsheikh et $\mathrm{al}^{29}$ & 2005 & 23 & 5 & 21.74 \\
\hline Talmi et a $\left.\right|^{30}$ & 1998 & 16 & 1 & 6.25 \\
\hline Silverman et al ${ }^{12}$ & 2003 & 16 & I & 6.25 \\
\hline Pantvaidya et $\mathrm{al}^{33}$ & 2014 & 121 & 6 & 5.00 \\
\hline Dabholkar and Kapre ${ }^{35}$ & 2016 & 29 & 3 & 10.34 \\
\hline Ghantous et $\mathrm{al}^{36}$ & 2016 & 8 & 1 & 12.50 \\
\hline Chiesa et $\mathrm{al}^{38}$ & 2000 & 11 & 1 & 9.09 \\
\hline Total cases & & 400 & 37 & \\
\hline
\end{tabular}

Abbreviation: SCC, squamous cell carcinoma.

patients who underwent a minimal SAN dissection had pain and shoulder dysfunction..$^{41}$ This may be due to traction and elevation of the nerve during dissection of the submuscular recess, namely, level IIb. Therefore, it is very significant to clarify whether to perform or avoid cervical level IIb dissection for the postoperative quality of life in patients with OSCC.
Tongue is the most common primary site for OSCC. Some studies reported that the primary site for level IIb metastasis has no statistical significance. ${ }^{26,35}$ But many scholars strongly recommended that dissection of level IIb in patients with tongue SCC should be incorporated into the procedures. Elsheikh et al found the incidence of metastasis at level IIb in patients with primary tumors located in the tongue to be $22 \%$. Thus, they defended that level IIb should be included in the neck dissection in the case of tongue cancer. ${ }^{29}$ Maher and Hoffman found cervical level IIb lymph node metastases in 4 of 71 (5.6\%) patients with primary OSCC and they also presented a relatively high incidence of level IIb metastasis from the tongue (11\%). ${ }^{21}$ Bhattacharya et al stated that tongue cancers and cancers of the retromolar trigone had the highest incidence of metastases at level IIb. ${ }^{26}$ However, Bartella et al demonstrated that metastases at level IIb resulted preferentially from malignant lesions on the soft palate, alveolar crest of the mandible and the buccal mucosa. ${ }^{22}$ In this analysis, it was found that the frequency of level IIb metastases of tongue SCC was higher than that of OSCC; tongue SCC patients, even in their early stages (T1 and T2), were prone to level IIb metastases. The possible reason for the propensity of tongue SCC to metastasize was that the tongue possesses extensive lymphatic network. Although there were still some other primary sites for OSCC

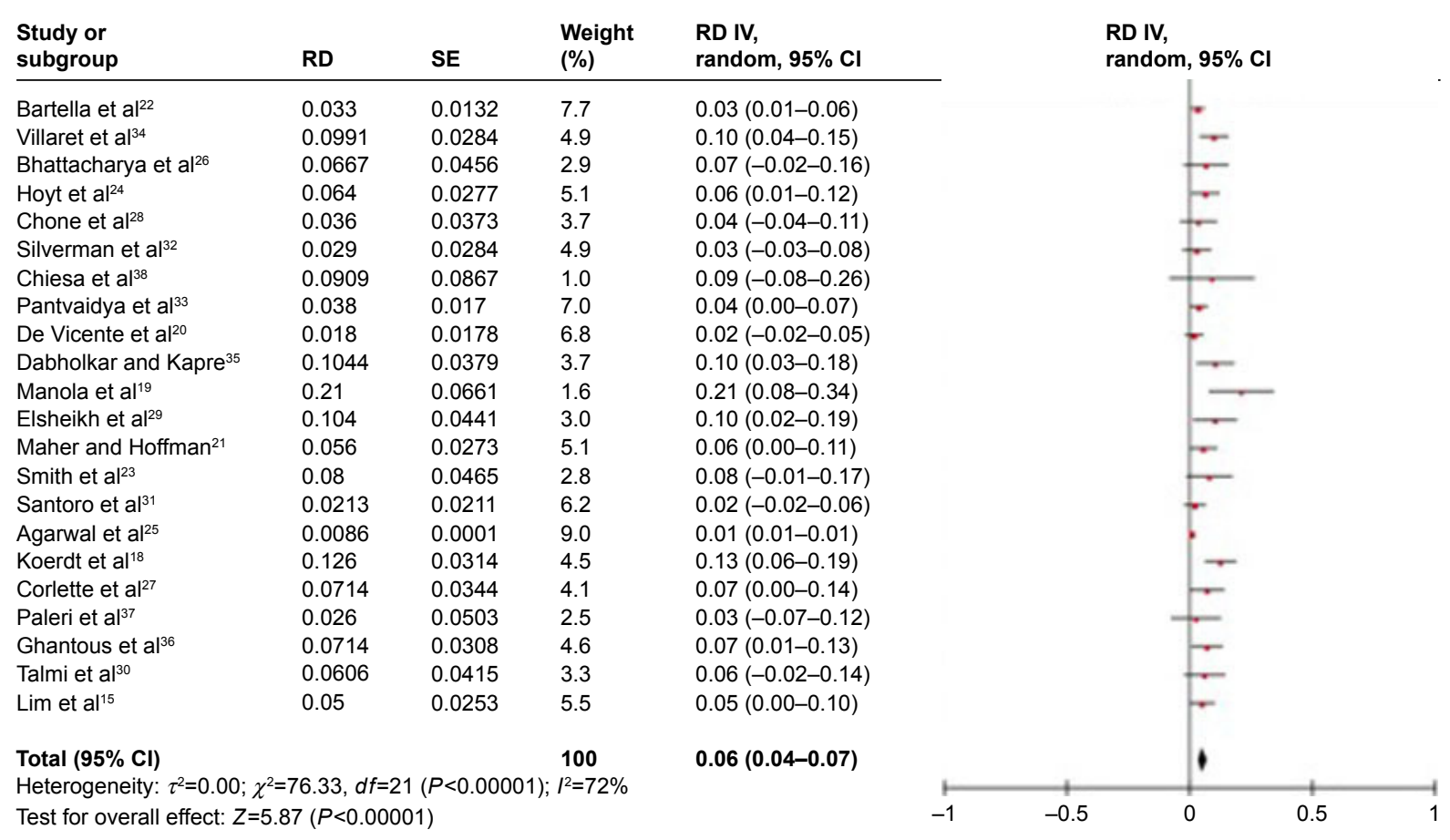

Figure 2 Forest plot for cervical level llb metastasis rate for OSCC.

Note: Chi-square based $Q$ test was used for heterogeneity evaluation of these studies $\left(\chi^{2}=0.00, P=72 \%, P<0.1\right)$, so the random effects model should be used and the cervical Ilb metastatic rate for OSCC was $6 \%$.

Abbreviations: $d f$, degrees of freedom; IV, inverse variance; OSCC, oral squamous cell carcinoma; RD, risk difference; SE, standard error. 


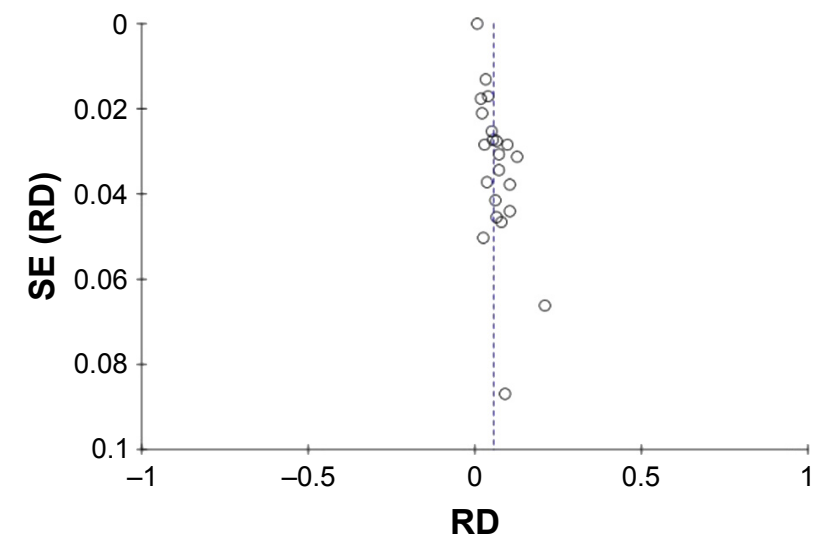

Figure 3 Funnel plot for cervical level llb metastasis rate for OSCC. Note: Plot indicates that there was no publication bias in these studies. Abbreviations: OSCC, oral squamous cell carcinoma; RD, risk difference.

patients with level IIb metastases, the number of cases was relatively low for each primary site and the patients were usually in terminal stages (T3 and T4). With no doubt, level IIb dissection should be routinely performed when patients have been found in their terminal stages, no matter where the primary sites are. However, when it comes to the cases in early stages, especially with N0 neck, researchers have different opinions about the extent of the neck dissection. ${ }^{42}$ Manola et al believed that sentinel node biopsy with the aid of lymphoscintigraphy appears to be a good technique for early tongue cancer. ${ }^{19}$ Yet, on the basis of our study, we suggest that level IIb dissection should better be performed in the case of tongue SCC, even in the early stages. Of course, our proposal still needs further verification due to the lesser number of cases of primary sites, except the tongue. More prospective, multicenter, large-scale trials would help to aid decision making for OSCC management in the future.
In this analysis, it was revealed that the prevalence of metastases at level IIb was low (6\%) and isolated level IIb metastases were rarely found. Thus, we suggest that it might not be always necessary to dissect level IIb lymph nodes in OSCC patients to avoid postoperative shoulder disability. Preservation of level IIb was conditional on the stages of primary lesions and the lymph node status. Level IIb dissection could be avoided when the primary lesions were in early stages, yet with the exception of tongue cancer, as we discussed earlier. Pantvaidya et al found that metastases at level IIb were associated with metastases at level IIa in $68.1 \%$ of dissections, while only $11.3 \%$ of all level IIa metastases had positive nodes at level IIb. ${ }^{33}$ Bhattacharya et al also reported that always there were positive nodes in level IIa in patients with positive level IIb nodes. ${ }^{26}$ So, it was proposed that the assessment of level IIa should be focused on using preoperative fine-needle aspiration cytology or intraoperative frozen section, thereby to guide further dissection of levels IIb and V. ${ }^{33}$ Level IIb dissection is recommended to be conducted in OSCC patients with multilevel neck metastasis, especially level IIa metastasis found preoperatively or intraoperatively.

The reason for the discrepancy in reported incidences of metastases may be partly due to the inconsistency of techniques utilized to detect the neck metastases. Traditional techniques for pathologic analysis of neck specimens by light microscopy with ordinary hematoxylin and eosin staining may fail to detect isolated micrometastases, while new and highly sensitive technologies such as immunohistochemical and molecular analysis may identify subpathologic micrometastases. Hence, the incidence of metastases detected

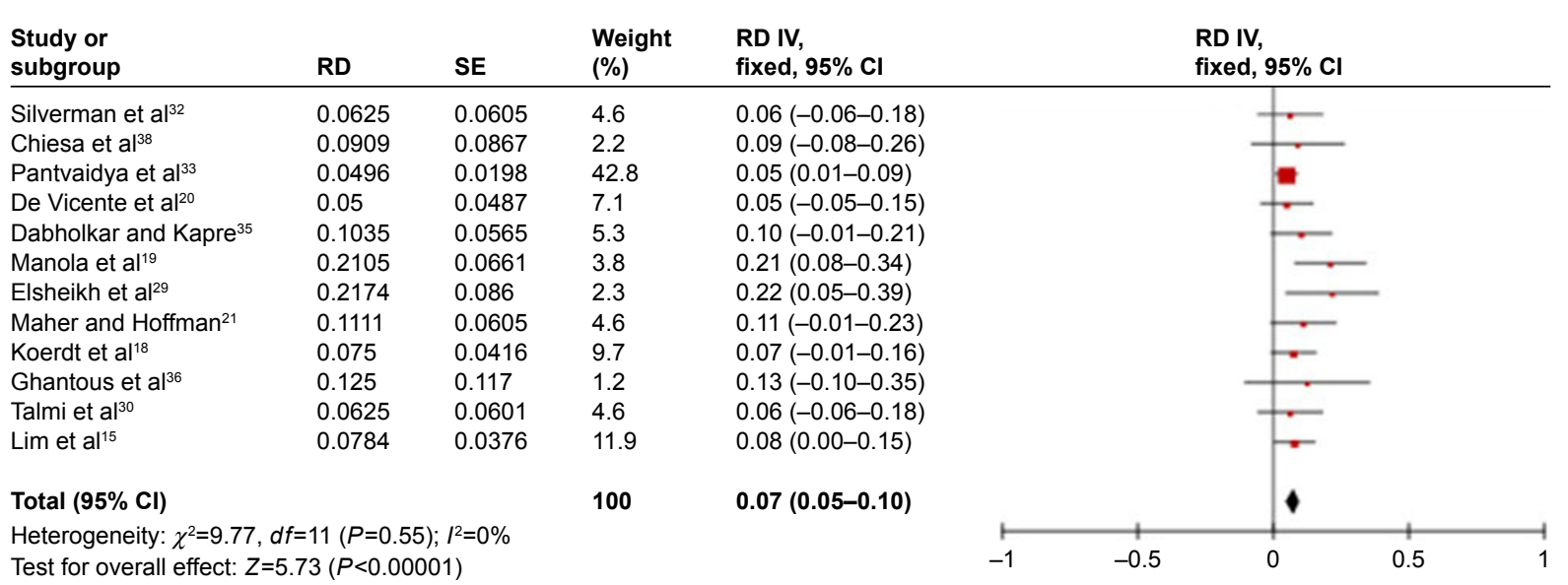

Figure 4 Forest plot for cervical level llb metastasis rate for tongue SCC.

Note: Chi-square based $Q$ test was used for heterogeneity evaluation of these studies $\left(\chi^{2}=9.77, P=0 \%, P<0.1\right)$, so the fixed-effects model was used and the cervical Ilb metastasis rate for tongue SCC was $7 \%$.

Abbreviations: $\mathrm{df}$, degrees of freedom; IV, inverse variance; SCC, squamous cell carcinoma; RD, risk difference; SE, standard error. 


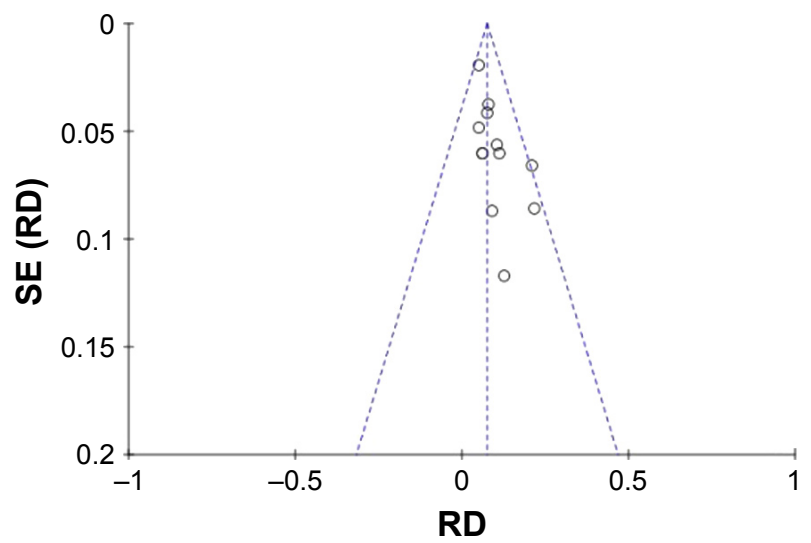

Figure 5 Funnel plot for cervical level Ilb metastasis rate for tongue SCC. Note: Plot indicates that there was no publication bias in these studies. Abbreviations: RD, risk difference; SCC, squamous cell carcinoma; SE, standard error.

has been found to be higher than previously indicated. ${ }^{43-46}$ Among the eight included studies which mentioned stain method, new technologies were used in two studies to detect metastases. Manola et al used molecular markers such as cytokeratin and epithelial membrane antigen and identified 8 cases with IIb metastases in 38 tongue SCC patients. ${ }^{19}$ Elsheikh et al found that the prevalence of metastases at level IIb was $6 \%(3 / 48)$ by pathologic analysis, but $10 \%(5 / 48)$ by CK20 nested reverse transcription-polymerase chain reaction, with the primary tumors located in the tongue. ${ }^{29}$ Thus, they stated that determination of CK20 gene expression by nested reverse transcription-polymerase chain reaction proved a good tool for detection.

It must be admitted that this study has limitations. First, there is inherent heterogeneity among the studies included. The inclusion and exclusion criteria, specimen processing methods and techniques for metastasis detection were variable. In addition, the limited data available and the relatively small sample size discounted the authority of this analysis. A large prospective multi-institutional cohort study with standardized intraoperative methods of dissecting level IIb and sensitive pathology detection for level IIb lymphonodus would help to make a definitive decision on the management strategy of OSCC in the future.

\section{Conclusion}

Based on the evidence that the frequency of level IIb metastasis in OSCC was low, level IIb dissection could be avoided when the primary lesions were in early stages ( $\mathrm{T} 1$ and $\mathrm{T} 2$ ), yet with the exception of tongue cancer. It is recommended to dissect level IIb for tongue cancers without considering the stages of primary lesions and the lymph node status. It is also suggested that level IIb dissection should be performed in patients preoperatively or intraoperatively found with multilevel neck metastases, especially IIa metastases. When considering the merits of preservation of level IIb, the benefit of preservation of SAN function has to be weighed against potentially reduced oncologic control.

\section{Disclosure}

The authors report no conflicts of interest in this work.

\section{References}

1. Kumar T, Patel MD. Pattern of lymphatic metastasis in relation to the depth of tumor in oral tongue cancers: a clinico pathological correlation. Indian J Otolaryngol Head Neck Surg. 2013;65(Suppl 1):59-63.

2. Massano J, Regateiro FS, Januário G, Ferreira A. Oral squamous cell carcinoma: review of prognostic and predictive factors. Oral Surg Oral Med Oral Pathol Oral Radiol Endod. 2006;102(1):67-76.

3. Okura M, Aikawa T, Sawai NY, Iida S, Kogo M. Decision analysis and treatment threshold in a management for the N0 neck of the oral cavity carcinoma. Oral Oncol. 2009;45(10):908-911.

4. Noguti J, De Moura CF, De Jesus GP, et al. Metastasis from oral cancer: an overview. Cancer Genomics Proteomics. 2012;9(5):329-335.

5. Li XM, DI B, Shang YD, Li J, Cheng JM. [Clinicopathologic features and prognostic factors of cervical lymph node metastasis in oral squamous cell carcinoma]. Ai Zheng. 2005;24(2):208-212. Chinese.

6. Tao L, Lefèvre M, Callard P, Périé S, Bernaudin JF, St Guily JL. Reappraisal of metastatic lymph node topography in head and neck squamous cell carcinomas. Otolaryngol Head Neck Surg. 2006;135(3): 445-450.

7. Woolgar JA. Histological distribution of cervical lymph node metastases from intraoral/oropharyngeal squamous cell carcinomas. $\mathrm{Br} \mathrm{J}$ Oral Maxillofac Surg. 1999;37(3):175-180.

8. Shah JP, Candela FC, Poddar AK. The patterns of cervical lymph node metastases from squamous carcinoma of the oral cavity. Cancer. 1990; 66(1):109-113

9. Carlson ER, Cheung A, Smith B, Pfohl C. Neck dissections for oral/ head and neck cancer: 1906-2006. J Oral Maxillofac Surg. 2006; 64(1):4-11.

10. Yu S, Li J, Li Z, Zhang W, Zhao J. Efficacy of supraomohyoid neck dissection in patients with oral squamous cell carcinoma and negative neck. Am J Surg. 2006;191(1):94-99.

11. Suen JY, Goepfert H. Standardization of neck dissection nomenclature. Head Neck Surg. 1987;10(2):75-77.

12. Robbins KT, Clayman G, Levine PA, et al. Neck dissection classification update: revisions proposed by the American head and neck society and the American Academy of Otolaryngology head and neck surgery. Arch Otolaryngol Head Neck Surg. 2002;128(7):751-758.

13. Cheng PT, Hao SP, Lin YH, Yeh AR. Objective comparison of shoulder dysfunction after three neck dissection techniques. Ann Otol Rhinol Laryngol. 2000;109(8 Pt 1):761-766.

14. Giordano L, Sarandria D, Fabiano B, Del Carro U, Bussi M. Shoulder function after selective and superselective neck dissections: clinical and functional outcomes. Acta Otorhinolaryngol Ital. 2012;32(6): 376-379.

15. Lim YC, Song MH, Kim SC, Kim KM, Choi EC. Preserving level IIb lymph nodes in elective supraomohyoid neck dissection for oral cavity squamous cell carcinoma. Arch Otolaryngol Head Neck Surg. 2004;130(9):1088-1091.

16. Santoro R, Franchi A, Gallo O, Burali G, de' Campora E. Nodal metastases at level IIb during neck dissection for head and neck cancer: clinical and pathologic evaluation. Head Neck. 2008;30(11):1483-1487.

17. Lea J, Bachar G, Sawka AM, et al. Metastases to level IIb in squamous cell carcinoma of the oral cavity: a systematic review and meta-analysis. Head Neck. 2010;32(2):184-190. 
18. Koerdt S, Röck1 J, Rommel N, Mücke T, Wolff KD, Kesting MR. Lymph node management in the treatment of oral cancer: Analysis of a standardized approach. J Craniomaxillofac Surg. 2016;44(10):1737-1742.

19. Manola M, Aversa C, Moscillo L, et al. Status of level IIb lymph nodes of the neck in squamous cell carcinoma of the oral tongue in patients who underwent modified radical neck dissection and lymph node sentinel biopsy. Acta Otorhinolaryngol Ital. 2011;31(3):130-134.

20. De Vicente JC, Rodríguez-Santamarta T, Peña I, Villalaín L, FernándezValle Á, González-García M. Relevance of level IIb neck dissection in oral squamous cell carcinoma. Med Oral Patol Oral Cir Bucal. 2015;20(5):e547-e553.

21. Maher NG, Hoffman GR. Elective neck dissection for primary oral cavity squamous cell carcinoma involving the tongue should include sublevel IIb. J Oral Maxillofac Surg. 2014;72(11):2333-2343.

22. Bartella AK, Kloss-Brandstätter A, Kamal M, et al. "IIb or not IIb" - The necessity of dissection in patients with oral squamous cell carcinoma. J Craniomaxillofac Surg. 2016;44(10):1733-1736.

23. Smith R, Taylor SM, Trites JR, Smith A. Patterns of lymph node metastases to the submuscular recess. J Otolaryngol. 2007;36(4):203-207.

24. Hoyt BJ, Smith R, Smith A, Trites J, Taylor SM. IIb or not IIb: oncologic role of submuscular recess inclusion in selective neck dissections. J Otolaryngol Head Neck Surg. 2008;37(5):689-693.

25. Agarwal SK, Arora SK, Kumar G, Sarin D. Isolated perifacial lymph node metastasis in oral squamous cell carcinoma with clinically nodenegative neck. Laryngoscope. 2016;126(10):2252-2256.

26. Bhattacharya A, Adwani D, Adwani N, Sharma V. Is it worthy? Removal of level IIB nodes during selective neck dissection (I-III) for oral carcinomas. Ann Maxillofac Surg. 2015;5(1):20-25.

27. Corlette TH, Cole IE, Albsoul N, Ayyash M. Neck dissection of level IIb: is it really necessary? Laryngoscope. 2005;115(9):1624-1626.

28. Chone CT, Crespo AN, Rezende AS, Carvalho DS, Altemani A. Neck lymph node metastases to the posterior triangle apex: evaluation of clinical and histopathological risk factors. Head Neck. 2000;22(6): 564-571.

29. Elsheikh MN, Mahfouz ME, Elsheikh E. Level IIb lymph nodes metastasis in elective supraomohyoid neck dissection for oral cavity squamous cell carcinoma: a molecular-based study. Laryngoscope. 2005;115(9): 1636-1640.

30. Talmi YP, Hoffman HT, Horowitz Z, et al. Patterns of metastases to the upper jugular lymph nodes (the "submuscular recess"). Head Neck. 1998;20(8):682-686

31. Santoro R, Franchi A, Gallo O, Burali G, de' Campora E. Nodal metastases at level IIb during neck dissection for head and neck cancer: clinical and pathologic evaluation. Head Neck. 2008;30(11):1483-1487.

32. Silverman DA, El-Hajj M, Strome S, Esclamado RM. Prevalence of nodalmetastases in the submuscular recess (level IIb) during selective neckdissection. Arch Otolaryngol Head Neck Surg. 2003;129(7): 724-728.
33. Pantvaidya GH, Pal P, Vaidya AD, Pai PS, D’Cruz AK. Prospective study of 583 neck dissections in oral cancers: implications for clinical practice. Head Neck. 2014;36(10):1503-1507.

34. Villaret AB, Piazza C, Peretti G, et al. Multicentric prospective study on the prevalence of sublevel IIb metastases in head and neck cancer. Arch Otolaryngol Head Neck Surg. 2007;133(9):897-903.

35. Dabholkar JP, Kapre NM. Level IIb neck dissection in oral cavity cancers-when should one address it? Indian J Surg Oncol. 2016;7(3): 303-306.

36. Ghantous Y, Akrish S, Abd-Elraziq M, El-Naaj IA. Level IIB neck dissection in oral squamous cell carcinoma: science or myth? J Craniofac Surg. 2016;27(4):1035-1040.

37. Paleri V, Kumar Subramaniam S, Oozeer N, Rees G, Krishnan S. Dissection of the submuscular recess (sublevel $\mathrm{IIb}$ ) in squamous cell cancer of the upper aerodigestive tract: prospective study and systematic review of the literature. Head Neck. 2008;30(2):194-200.

38. Chiesa F, Mauri S, Grana C, et al. Is there a role for sentinel node biopsy in early N0 tongue tumors? Surgery. 2000;128(1):16-21.

39. Lloyd S. Accessory nerve: anatomy and surgical identification. J Laryngol Otol. 2007;121(12):1118-1125.

40. Leipzig B, Suen JY, English JL, Barnes J, Hooper M. Functional evaluation of the spinal accessory nerve after neck dissection. Am J Surg $1983 ; 146(4): 526-530$.

41. Kraus DH, Rosenberg DB, Davidson BJ, et al. Supraspinal accessory lymph node metastases in supraomohyoid neck dissection. Am J Surg. 1996;172(6):646-649.

42. Weiss MH, Harrison LB, Isaacs RS. Use of decision analysis in planning a management strategy for the stage N0 neck. Arch Otolaryngol Head Neck Surg. 1994;120(7):699-702.

43. Ambrosch P, Brinck U. Detection of nodal micrometastases in head and neck cancer by serial sectioning and immunostaining. Oncology (Williston Park). 1996;10(8):1221-1226.

44. Yoshida K, Kashima K, Suenaga S, Nomi N, Shuto J, Suzuki M. Immunohistochemical detection of cervical lymph node micrometastases from T2N0 tongue cancer. Acta Otolaryngol. 2005;125(6):654-658.

45. Rhee D, Wenig BM, Smith RV. The significance of immunohistochemically demonstrated nodal micrometastases in patients with squamous cell carcinoma of the head and neck. Laryngoscope. 2002;112(11): 1970-1974.

46. Ferlito A, Rinaldo A, Devaney KO, Nakashiro K, Hamakawa H. Detection of lymph node micrometastases in patients with squamous carcinoma of the head and neck. Eur Arch Otorhinolaryngol. 2008; 265(10):1147-1153
OncoTargets and Therapy

\section{Publish your work in this journal}

OncoTargets and Therapy is an international, peer-reviewed, open access journal focusing on the pathological basis of all cancers, potential targets for therapy and treatment protocols employed to improve the management of cancer patients. The journal also focuses on the impact of management programs and new therapeutic agents and protocols on

\section{Dovepress}

patient perspectives such as quality of life, adherence and satisfaction. The manuscript management system is completely online and includes a very quick and fair peer-review system, which is all easy to use. Visit http://www.dovepress.com/testimonials.php to read real quotes from published authors. 